Please cite as: Jaspal, R., Nerlich, B. \& Cinnirella, M. (in press). Human Responses to Climate Change: Social Representation, Identity and Socio-Psychological Action.

Environmental Communication: A Journal of Nature and Culture.

\title{
Human Responses to Climate Change: Social Representation, Identity and Socio- Psychological Action
}

Rusi Jaspal, Brigitte Nerlich and Marco Cinnirella

\begin{abstract}
Climate change is one of the most important global challenges in the twenty-first century, given that a changing climate is likely to have negative and potentially irreversible consequences for the environment and human beings. Drawing upon Social Representations Theory and Identity Process Theory from social psychology, we argue that research should focus upon, and successfully integrate, three levels of analysis, namely (1) how climate change knowledge is constructed and circulates (social representation); (2) the role of identity in relation to these representations (identity); and (3) how people might respond to them (action). It is suggested that identity processes may determine how people process social representations of climate change, and that they mediate the link between representations and environmental behaviour. Understanding human responses to climate change necessitates an integrative social sciences perspective, in terms of disciplinary, theoretical and methodological approaches.
\end{abstract}

Keywords: climate change; communication; social representation; identity; social action; identity process theory; public understanding; behaviour change

Rusi Jaspal is Lecturer in Psychology, Faculty of Health and Life Sciences, De Montfort University, Brigitte Nerlich is Professor of Science, Language and Society, Faculty of Social Sciences, University of Nottingham and Marco Cinnirella is Senior Lecturer in Psychology, Department of Psychology, Royal Holloway, University of London. Correspondence to Dr Rusi Jaspal, School of Applied Social Sciences, Faculty of Health and Life Sciences, De Montfort University, Leicester LE19BH, United Kingdom.E-mail: rusi.jaspal@,cantab.net

\section{Introduction}

Climate change is one of the most important global challenges in the twenty-first century, yet an understanding of public reactions to this issue remains noticeably incomplete. Public resistance to changing relevant behaviours remains a key issue for research, especially given apparent increases in public awareness of the scientific arguments (Exley \& Christie, 2003). Recently, scholars have argued that climate change communicators should take into 
consideration the prevailing attitudes, values and psychological 'needs' of their audiences (Crompton \& Kasser, 2010; Kahan, 2010). This paper attempts to complement this research by marrying a variety of theoretical observations in an integrative model which links social representation, self-identity and socio-psychological action. These three factors have not yet been studied extensively in the context of climate change and the links between them have not been studied at all. In this article we show how these factors may help determine how individuals and groups deal with climate change as a complex problem and make it their own.

We outline these different levels of analysis in an integrative model, which we apply to existing research on climate change, and provide the theoretical tools for future empirical research. This paper provides a critical synthesis of current debates around identity and social representations and applies them to the issue of climate change communication, focusing in particular on the development of social representations and processes of identity formation. We want this paper to initiate sa conversation and stimulate empirical research.

\section{Social Representations of Climate Change}

Social sciences approaches to climate change are concerned with understanding how this environmental problem is represented in society, on the one hand, and how people think and feel about it, on the other. Our theoretical model strives to address both of these issues within an integrated framework that draws upon Social Representations Theory (SRT). SRT treats seriously the information that circulates in society (e.g. in the media, in school textbooks and literature) and the ideas in people's minds (Moscovici, 1988). It provides a framework for 
understanding and exploring how scientific knowledge, such as that associated with the climate change debate, diffuses in society and can become associated with intergroup power struggles. A social representation is defined as a system of values, ideas and practices regarding a given social object, as well as the elaboration of that object by a group for the purpose of communicating and behaving. Accordingly, it provides a given group with a shared social 'reality' and 'common consciousness' vis-à-vis a particular social object.

SRT was originally designed to understand how constructs and theories pertaining to the scientific domain make their transition into public discourse and layperson 'commonsense', hence it is well placed to offer insights into the public understanding of climate change. Social representations of climate change facilitate sense-making of a potentially obscure and esoteric environmental phenomenon originating from the scientific domain. An SRT approach to climate change enables researchers to gain insights into the ways in which climate change is represented in channels of societal information and the ways in which it is deployed cognitively and rhetorically by social actors in communication (Jaspal \& Nerlich, 2013; Olausson, 2011; Smith \& Joffe, 2013).

\section{Constructors of Social Representations}

Social representations exist at the level of groups and individuals and facilitate communication. Sources of societal information such as the media can help develop social representations, since "[a]s a forum for the discourses of others and a speaker in their own right, the media have a key part in the production and transformation of meanings" 
(Carvalho, 2007, p. 224). Furthermore, it is necessary to "properly acknowledge the news media as the primary intermediary between science, politics, and the citizens, as well as their agenda-setting role for citizens' meaning making on climate change" (Olausson, 2011). Yet, both the media and individuals function as co-constructors of social representations (Breakwell, 2001), and there is an important and dynamic interplay between media representation, identity and personal experience (Smith \& Joffe, 2013).

Social representations can develop and change over time and, unless 'hegemonic' (dominant), are open to contestation and re-formulation in everyday discourse (Marková, 2003). They provide the backdrop against which individuals and groups develop their own beliefs (Jaspal, Nerlich \& Koteyko, 2013). It is therefore important to understand the available repertoire of social representations of climate change in particular contexts, through the analysis of print media and television coverage, for instance. Some SRT researchers of climate change have begun to do this (e.g. Höijer, 2010; Jaspal \& Nerlich, 2013; Olausson, 2010, 2011).

\section{Types of Social Representation}

Moscovici (1988) has postulated three types of social representation: hegemonic, emancipated and polemic. A hegemonic representation is one that is shared consensually by members of a group; they are coercive and uniform. The notion that the climate is changing largely as a result of human-induced industrial developments in the Western world constitutes a hegemonic representation within the global scientific community (Houghton et al., 2001), 
although the status of this representation seems to be different in the US (Leiserowitz, 2005). An emancipated representation is developed by subgroups within a larger social collective as a result of outgrowths of information and distinctive knowledge within these subgroups. Emancipated representations constitute 'developments' or minor amendments of the overarching hegemonic representation. For instance, while the hegemonic representation is that anthropogenic climate change will have negative outcomes, an emancipated representation among Maldiveans (a subgroup within the superordinate community of 'believers') is that climate change is likely to result in the complete submergence of the Maldives resulting in a massive refugee problem (Minivan News, 2012). A polemic representation is one which is generated in the course of social conflict, and characterised by antagonistic relations between groups. A vivid example of this is the rivalry between the majority of climate scientists, who argue that climate change is dangerous and largely dependent upon human activities, and climate critics, who challenge the legitimacy of this hegemonic representation (Jaspal et al., 2013; McCright, 2007).

Hegemonic, emancipated and polemic representations seem to affect the climate change agenda differently. Hegemonic representations are usually more likely to shape attitudes because they are coercive, shared at a mass scale and thus difficult to re-construe or reject (Breakwell, 2001). Conversely, polemic representations are often perceived as being peripheral to 'mainstream' thinking and thus unworthy of attention (e.g. McCright, 2007). Thus, it is plausible that relevant groups may attempt to 'upgrade' their polemic or 
emancipated representations of climate change to hegemonic status in order to advance their personal/collective goals (Jaspal et al., 2013).

The representational field in which climate change as a social and cultural issue is located seems to be characterised by all three kinds of social representation (Hulme, 2009). Polemic representations can rise in prominence and gradually become hegemonic due partly to the media's balancing norms, whereby 'both sides of the story' are presented in order to safeguard 'objectivity' (Boykoff \& Boykoff, 2004). The psychologically preferable, though scientifically indefensible representation may ultimately be adopted by the general population. Conversely, the representation that is grounded in science and empiricism may be ousted from its hegemonic position. This paper examines how and why this may happen.

\section{Processes of Social Representational Formation}

Two socio-psychological processes underlie the formation of representations, namely anchoring and objectification. Understanding how these processes function in relation to climate change is important (Höijer, 2010). Anchoring reflects the categorisation of unfamiliar objects through their comparison with an existing stock of familiar and culturally accessible objects. Recent empirical studies have demonstrated a widespread tendency for individuals to anchor climate change to ozone depletion, which constitutes the basis of their understanding of climate change, especially in the UK context (Lorenzoni et al., 2006; Smith \& Joffe, 2013. This highlights the importance of a culturally sensitive, relativist epistemological approach to representations of climate change. In Germany, for example, a 
group of scientists constructed climate change in terms of an 'impending climatic catastrophe' by anchoring it to extreme weather events, such as flooding, in 1987, and the resultant social representation affected political discourse surrounding climate change (Weingart, Engels \& Pansegrau, 2000). Thus, the 'catastrophe' anchoring clearly has an important role to play in rendering the global challenge of climate change culturally and psychologically accessible to laypeople, but is generally rejected by climate critics.

Objectification transforms unfamiliar and abstract objects into concrete and 'objective' common-sense realities. Moscovici and Hewstone (1983) have identified three sub-processes associated with objectification, namely personification of knowledge, figuration and ontologisation. Personification of knowledge links the abstract object to a person or a group, providing the object with a more concrete existence through this association. For instance, the former US presidential candidate Al Gore has, in many ways, served as a personification of the climate change debate in the US both in terms of a rallying point for those who aim to mitigate the effects of climate change and for those who are sceptical of such endeavours.

Furthermore, recent media analyses have demonstrated that the objects of social representation (e.g. the planet) can also be personified in order to achieve emotive rhetorical effects (Jaspal \& Nerlich, 2013). Figuration refers to the process whereby an abstract object is dominated by metaphorical imagery, which renders it more psychologically and culturally accessible. For instance, in her discussion of bloggers' responses to the 'Climategate' affair, Nerlich (2010) notes the repeated use of the religious metaphor 'preaching' in relation to 
climate change communication. This provides a concrete image for scientific dissemination of climate change, constructing it as speculative, unscientific and irrational. Ontologisation refers to the process whereby physical characteristics are attributed to something nonphysical, essentially 'materialising' the immaterial. In her analysis of the Swedish press, Olausson (2010, p. 146) observes that climate change is ontologised in terms of 'smoke stacks, exhaust pipes, heavy vehicles and smoke', suggesting its overall objectification in terms of perceptible and visible pollution. In media and layperson discourses, the processes of anchoring and objectification have engendered particular social representations of climate change.

\section{A Key Social Representation of Climate Change}

Existing SRT research into climate change communication suggests the existence of some key social representations in Western industrialised societies (Höijer, 2010; Olausson, 2010, 2011; Smith \& Joffe, 2013. The notion that anthropogenic climate change is largely a human-induced environmental problem constitutes a hegemonic representation, which has been encouraged since at least 1988 (Jaspal \& Nerlich, 2013). However, this representation is habitually contested in public, media and political discourse by competing polemic representations. For instance, some climate critics tend to emphasise the 'natural' (cyclical) dimension of climate change and to attenuate the human contribution to it (McCright, 2007). Therefore, the polemic representation has infiltrated public understanding. Bostrom (2001) reports the results of a national survey of American adults in 1995, which revealed that $42 \%$ 
of respondents attributed climate change to both 'natural' processes and human activities, $18 \%$ attributed it solely to nature, and the remaining $40 \%$ believed that human behaviour was the major cause of climate change. These data, though somewhat dated, suggest that there have been at least three understandings of the causes of climate change. The hegemonic representation of anthropogenic climate change might encourage individuals to re-think their own behaviour and to engage in some form of mitigation. Conversely, polemic representations that attach greater priority to natural processes are likely to encourage individuals to do nothing, since any attempt to mitigate climate change is regarded as futile. Interestingly, Bostrom and Lashof (2007) argue that (social representational) conflation between climate and weather, which is widespread in media and public discourse, may in fact lead the public to consider climate change as unrelated to human conduct and, thus, uncontrollable.

The hegemonic social representation of anthropogenic climate change gives rise to an understanding that in order to mitigate climate change, individuals will need to change their behaviour and that national and regional institutions will need to re-think current economic and industrial policies. The particular sorts of change required constitute the peripheral elements of this social representation. For instance, Abrahamse et al. (2009) discusses the role of meat consumption in human-induced climate change, while the UNFCCC's Kyoto Protocol stipulated obligatory emissions reduction targets for participating countries. International organisations and national governments generally agree that emissions reductions are a necessary mitigation strategy at the institutional level (although 
policy initiatives regarding mitigation vary). This stance is challenged by the competing polemic representations associated with conservative think tanks in the US, which question the reality of climate change.

Some scholars argue that it is important to encourage 'alarming' social representations, given that climate change is alarming (Risbey, 2008). Conversely, Bostrom and Lashof (2007) make the observation that promoting representations of catastrophe and calamity in climate change communication in the absence of information concerning causality or mitigation strategies can prove ineffective and counterproductive (see also Moser, 2007). Empirical studies have shown that inducing fear can change people's attitudes and affect their stated concerns at the verbal level, but there is little evidence that this induces long-term behaviour change (Ruiter, Abraham \& Kok, 2001). In order to facilitate change, Leiserowitz (2007) argues, communicators ought to highlight the potential local and regional impact of climate change, which essentially renders climate change a relevant and noteworthy issue for the group targeted. This implicitly highlights the potential role of identity - local, regional, group identities - in determining how people will view and respond to climate change.

Social representations of climate change alone cannot be regarded as catalysts for behaviour change (Dunwoody, 2007). Rather, researchers must factor into any model of communication, understanding and action the role of identity processes which likely mediate the relationship between social representation and action (Breakwell, 2010). Particular socio- 
psychological factors govern the internalisation, acceptance and rejection of these representations. The next section of the paper explores some of these factors.

\section{Identity: Individual and Group Levels}

Leiserowitz (2007, p. 57) has argued that an important strategy for optimising climate change communication is to 'tailor messages and messengers for particular interpretive communities'. He argues that groups who share particular risk representations, values and socio-demographic characteristics might respond to climate change representations in similar ways (Leiserowitz et al., 2012). However, this approach overlooks the agentive role of identity in human responses to climate change. By identity, we mean the total identity of the individual that comprises social group memberships, interpersonal relations, exposure to social representations and individual behaviour (Jaspal \& Breakwell, 2014).

Individuals are not just passive recipients of representations but rather they play an active role in constructing and contributing to them. Moreover, they filter them through particular interpretative lenses which themselves are the product of identity (Agyeman et al., 2007). Here it is argued that the missing link between social representations and social action may be identity. We begin by discussing group memberships as aspects of identity, followed by the predictable states of identity that are sought by individuals, and how they may be affected by particular representations of climate change 


\section{Groups and Social Representations}

In her synthesis of SRT and the social identity approach, Breakwell (1993) describes the dynamic process of social representational formation at the level of the social group. The social group level is important because category memberships form part of the total identity of the individual. Social representations intersect both discourse and human perception - they are constructed in the media and through everyday layperson talk and are, therefore, the product of the dialectics between the two (Marková, 2003). Yet, it is also true that groups can engineer and encourage representations, which are consistent with their aims and interests (Breakwell, 1993). Accordingly, it is important to examine the intergroup power differentials characterising relations between groups involved in social representational formation. More powerful social groups (e.g. climate think tanks) in the climate debate will have the power to shape decisively the formation of representations of climate change and to impose them upon less powerful groups (e.g. laypeople).

Group power is a complex phenomenon. In the climate debate, climate scientists might plausibly be said to constitute a 'powerful' group, given the positive cultural constructions of science (Irwin, 1995), while sceptical laypeople may be thought of as less 'powerful'. However, in the context of climate change communication, the aforementioned group power hypothesis becomes less straightforward. Boykoff and Boykoff (2004) have shown how the journalistic norm of 'balanced reporting', whereby both sides of an argument are often afforded equal space and attention in the media, may skew public understanding in favour of what might usually be regarded as the 'less powerful' (i.e. climate critics) group in 
the climate debate. This has been attributed to the observation that some climate sceptics or critics discursively exploit the scientific uncertainty which characterises the talk of climate scientists, as a means of constructing scientific observations concerning climate change as unreliable conjecture rather than 'hard, indisputable science' (Dryzek, Norgaard \& Schlosberg, 2011). This is further reinforced by the successful mobilisation of antienvironmental movements in the US, despite contrary assertions from climate scientists (McCright, 2007). In order to understand why groups might make use of their 'power' in order to project particular representations, it is useful to examine the functions served by social representations of climate change for the social groups and individuals involved in the debate.

Although groups sometimes engineer social representations to suit their agendas, it is true that social representations form organically in everyday communication. Thus, it is equally as important to examine the involuntary or 'secondary' effects that social representations can have for relevant social groups. For instance, reproducing the social representation that climate change is a myth can induce the de-legitimisation of climate scientists who conversely argue that climate change is a human-induced environmental problem. De-legitimisation can entail attributing negative characteristics to a group; categorising groups represented as contradicting the in-group 'worldview' as violators of key norms; and anchoring groups to existing groups that are already delegitimised in a given society. Some climate sceptics attempt to rationalise rhetorically their position in relation to climate change and to lend it credibility by reproducing social representations that contradict 
those associated with climate scientists (McCright, 2007). Their reproduction of these representations can serve to delegitimise climate scientists, since they may be attributed negative characteristics such as 'fundamentalist' (Nerlich, 2010) or constructed as violating the norm of scientific professionalism (Jaspal et al., 2013).

However, groups do not function without individuals and group memberships form part of the total identity of the individual - thus, it is also necessary to examine the role of the individual in relation to social representation.

\section{Personalising Social Representations}

Given the dialectic relationship between media representation and perception, it is necessary to theorise how individuals might negotiate and respond to media content and other forms of representation (Olausson, 2011). Breakwell (1993, 2001) has outlined how individuals "personalise" social representations. Her model suggests that an individual's relationship with a social representation can be described in terms of the following five dimensions: (i) awareness; (ii) understanding; (iii) acceptance; (iv) assimilation; and (v) salience.

Individuals differ in their awareness of a given social representation. Some may never encounter a social representation, while others may have full or at least partial knowledge of it. Awareness can be affected by a number of factors, such as previous personal experience of the 'object' of social representation or membership in particular social groups which provide access to the representation. However, awareness, though important, does not necessarily lead to behavioural change (Thrush et al., 1999). 
In addition to awareness, individuals will manifest distinct levels of understanding in relation to the representation, which might not correlate neatly with awareness levels. For instance, research shows that, although some 90 percent of the US population have heard about climate change, a significantly smaller percentage knows that the problem is related to energy use or that it could entail irreversible environmental consequences (Leiserowitz, 2003). Indeed, a key debate concerns more 'effective' communication in order to enhance public understanding of climate change, given that there is much discrepancy in levels of understanding (Moser \& Dilling, 2007). The information deficit model suggests that communicators ought to enhance public understanding of climate change by providing more information (Lazo, Kinnell \& Fisher, 2000). However, public understanding of the links between personal behaviour and climate change seem to be of greater relevance than understanding of the physics of climate change itself. Individuals may prefer and prioritise social representations that they more fully understand than those which are cognitively inaccessible (cf. Kahan et al., 2011).

Acceptance of a given social representation relates to the individual's belief system. People can exhibit awareness and understanding of a given social representation, while accepting an alternative, contradictory representation. This is observable in individuals' (re-)production of conspiracy theories regarding climate change, namely that scientists fabricate statistics in order to protect their careers (Jaspal et al., 2013). Although climate critics are acutely aware of the hegemonic representation of anthropogenic climate change, some sceptics attribute this representation to a 'malevolent' out-group, namely climate 
scientists (Leiserowitz, 2006). As Nerlich's (2010) work shows, subsequent to 'Climategate', many bloggers rejected this hegemonic representation in favour of the polemic representation that human-induced climate change constitutes a myth or conspiracy. Breakwell (2001, p. 273) notes that the alternative contradictory representation may 'share many of the common features of the [existing] social representation'. Indeed, sceptics do not necessarily reject the notion that the climate is changing, but they do often problematise the central dimension of the hegemonic representation concerning human agency in climate change (McCright, 2007).

Like acceptance, the assimilation of a social representation is pertinent to the individual's belief system. Acceptance does not automatically lead to assimilation. It is possible to accept that human behaviour has contributed to climate change but to refuse to assimilate this representation within one's existing network of knowledge. Knowledge and assimilation of the representation can be suppressed in order to avoid taking a 'stance' (see Breakwell \& Millward, 1997). When a representation is assimilated at the individual level, 'cognitive and emotional processes ensure that it is anchored in prior personal representations' (Breakwell, 2001, p. 273). In their UK-based interview study, Poortinga et al. (2011) found that politically conservative attitudes and traditional values seemed to shape people's responses to social representations of climate change. More specifically, individuals with these attitudes and values were more likely to manifest scepticism in relation to climate change, although they did not necessarily deny its existence. Crucially, these respondents did accept representations of climate change but it was the assimilation of these representations to pre-existing attitudes and values (namely political conservatism and traditional values) that 
seemed to induce scepticism. Research thus suggests that a social representation must first be assimilated in order for changes to take place within the identity structure for its accommodation (Breakwell, 1986). In the next subsection, we provide insight into the factors which seem to predict the assimilation of social representations.

The salience of a representation will differ across different individuals and groups, as well as across distinct temporal and socio-cultural contexts. Breakwell (2001) states that a social representation can acquire salience if it becomes relevant to the on-going activities of a group or individual. For instance, in the Maldives significant political and media attention to climate change has rendered salient representations of climate change among islanders (Pernetta, 1992). Conversely, Norgaard (2011) has observed in her study of a small town in Norway that, since climate change is not perceived as relevant to their ongoing activities, many inhabitants simply do not think about it and, thus, representations of it are latent. The anchoring process may actually render salient social representations of climate change, particularly if climate change is anchored to a phenomenon which is personally relevant, such as a personal experience of flooding, for instance (Whitmarsh, 2008).

The personalisation of social representations seems to be associated with the human tendency to protect identity processes (Breakwell, 2010). This is described next.

\section{Identity Processes}

Crompton and Kasser (2010) have argued that it is necessary to ascertain which elements of an individual's identity will be threatened by tenets of climate science if we are to predict 
their responses to climate change. Empirical research suggests that the acceptance and assimilation of social representations are guided by identity processes (Breakwell, 2001). Identity Process Theory (IPT) (Breakwell, 1986, 1993, 2001; Jaspal \& Breakwell, 2014) provides an integrative theory of identity construction, threat and coping, by outlining: (i) the necessary components of a positive identity; (ii) social situations likely to 'threaten' identity and; (iii) the strategies likely to be implemented by the individual in order to cope with the threat. According to IPT, identity is guided by two processes: (i) the assimilationaccommodation process refers to the absorption of social stimuli (i.e. social representations of climate change) in the identity structure and the adjustment which takes place in order for it to become part of the structure; and (ii) the evaluation process confers meaning and value upon these contents of identity.

The processes of assimilation-accommodation and evaluation are guided by a series of identity principles, which are essentially desirable 'end-states' for identity. Breakwell (1986) originally identified four identity principles and argued that individuals need to perceive appropriate levels of: (i) self-continuity and group-continuity across time (continuity); (ii) uniqueness and differentiation from relevant others (distinctiveness); (iii) competence and control over their lives (self-efficacy); (iv) feelings of personal worth (selfesteem). In subsequent research, additional principles have been proposed but are not consensually acknowledged as part of IPT (Jaspal \& Breakwell, 2014). These include (i) significance and purpose (meaning); and (ii) belonging within social groups (belonging); and 
(iii) compatibility and coherence between elements of their identities (psychological coherence).

Whereas some existing work on environmental behaviours makes use of perhaps one or two similar constructs, such as efficacy and control, few, if any, such studies draw upon a coherent multi-level model such as IPT. Thus, for example, while Wall et al. (2007) argued that their study of car use choices in the UK highlighted the importance of personal obligation, altruism and a sense of control, we would argue that these are not just individual level variables, but that they are informed by relevant social representations, and the degree to which the individual endorses these as part of their on-going strategy to maintain and serve the identity principles laid out in IPT.

IPT posits that if the individual cannot perceive appropriate levels of sociopsychologically salient principles, identity is threatened, which is aversive for psychological well-being. Accordingly, the individual will attempt to minimise threat by engaging in coping strategies.

While studies deploying models of values and altruism (e.g. the value belief norm theory of environmentalism, Stern, 2000) provide interesting insights into pro-environment behaviour, we argue they are too often focused on intra-psychic mechanisms and thus provide just one part of the picture. Furthermore, while some approaches to encouraging environmentally aware behaviours suggest finding ways to encourage individuals to 'put on hold' individual needs (Steg \& Gifford, 2008), in contrast, our hybrid theoretical approach suggests that individuals will always be motivated to protect identity principles. Therefore, 
rather than somehow aiming to turn off individual identity motives, a more adequate approach is to understand how pro-environmental behaviours can come to be seen as serving identity principles, while simultaneously ensuring that such behaviour does not threaten valued identity principles.

Given the centrality of human agency in constructing, monitoring and protecting identity (Breakwell, 1986), individuals will attempt to accept and assimilate those social representations that do not threaten these desirable identity end-states. For example, the alarmist representation that climate change will devastate the planet and result in large-scale catastrophe may plausibly threaten the group continuity principle, since the individual is led to believe that his or her immediate in-groups may cease to exist in the long-run. Moreover, the threat is likely to be chronic if there is no obvious 'solution' to climate change or mitigation strategy (Nicholson-Cole, 2004). Given its negative implications for the continuity principle, it is possible that this social representation will frequently be rejected by the individual. Breakwell's (2001) model of personalisation is useful in illustrating how even those social representations which are not accepted and assimilated by individuals can nonetheless continue to jeopardise identity. Although the individual may reject the representation, at the social level it may remain salient through media reporting and interpersonal communication, which enables the representation to continually threaten identity.

Similarly, the hegemonic representation of anthropogenic climate change generally advocates some form of behaviour change at both public and institutional levels. Enforced 
behaviour change can potentially jeopardise the unifying psychological thread between past, present and future given that one's lifestyle can become entrenched in one's daily routine and overall sense of self. Often the changes required are regarded as 'too radical' and excessively disruptive for one's sense of self. Behaviour change which interferes with one's daily life convenience is likely to be construed as particularly threatening (Bord et al., 2000). The continuity principle may motivate individuals to reject the representation that major behaviour change is needed and instead accept and assimilate the contradictory representation that only 'small changes' are necessary for mitigation or adaptation. Furthermore, the enforced reduction of the use of fossil fuels could jeopardise self-efficacy and distinctiveness at the group level, since it may be regarded as threatening the unique economic competence and hegemony of one's nation (e.g. in the U.S. context).

In considering representations of mitigation techniques, which typically point to some form of behaviour change, it seems likely that some may be construed as threatening for identity among particular groups and individuals. For instance, the IPCC has recommended that members of the general public should refrain from consuming meat at least one day a week in order to make an effective personal contribution to climate change mitigation. However, in some socio-cultural contexts prevalent social representations of meat may render this problematic for identity due to meat consumption being associated with masculinity (Abrahamse et al., 2009), with abandonment of meat consumption therefore potentially threatening the continuity and distinctiveness principles of identity. 
Murtagh, Gatersleben and Uzzell (2012) state that convincing the general public to re-think travel behaviour could lead to decreased carbon emissions with favourable outcomes for the environment. However, they acknowledge the potential threats to continuity, distinctiveness and self-esteem, which may be entailed by behaviour change and the adoption of sustainable pro-environmental behaviours. Similarly, in their investigation of motivations and barriers to adopting sustainable travel behaviour, Prillwitz and Barr (2009) highlight the potential impact of psychological attachment to one's car as a variable affecting travel behaviour change, given that the car can, for some individuals, constitute an important element of identity.

Given the complexity of identity processes, people may respond to representations of climate change in equally complex ways. The need for acceptance and inclusion in particular social circles (the belonging principle) might motivate some individuals to accept social representations of anthropogenic climate change. This is observable among young Britons of middle-class background, whose concern for environmental issues has been attributed to fear of alienation from society (Eckersley, 1989). Social desirability effects have been observed in survey-based research into environmental problems with some participants allegedly 'overstating' their environmental concerns (Sterngold et al., 1994).

Alarmist representations of climate change seem to jeopardise the self-efficacy principle of identity and lead to disempowerment of social actors (Milne, Sheeran \& Orbell, 2000). Yet, self-efficacy seems to be important in the context of climate change (Breakwell, 2010). Moser (2007) argues that threat representations are most likely to be effective in 
causing persistent attitude change and in motivating 'constructive' responses when people regard themselves as being in control and competent (self-efficacy). This hypothesis reinforces the assertion that alarmist representations of climate change can be counterproductive (Hulme, 2009).

The remainder of the paper now turns to an exploration of the patterns of sociopsychological action which may ensue from human exposure to social representations of climate change.

\section{Socio-Psychological Action}

Here we provide some insight into potential socio-psychological strategies for dealing with real or anticipated threat to identity as a result of representations of climate change. For reasons of space, we can only provide a sketch of major trends in research.

\section{Behavioural Predictors}

The information deficit model postulates that individuals lack sufficient information to engage with climate change adequately (Lazo et al., 2000), and thereby assumes a straightforward relationship between awareness of social representations and behaviour. However, empirical research demonstrates that risk representations are generally poor predictors of behaviour, with examples in the fields of sexual behaviour (Breakwell \& Millward, 1997) and smoking (Hansen et al., 2010). These studies converge in showing that where a behaviour is perceived as important to self-esteem and other principles, it is likely to 
persist, despite awareness of potential risks. Thus, in addition to considering risk representations, it is necessary for the researcher to examine the ways in which particular behaviours (e.g. use of one's car; the consumption of meat) might impinge upon identity processes in specific socio-cultural settings. This can enable the researcher to predict the adoption or avoidance of pro-environmental behaviours. The more a change is construed as threatening for identity, the less willing one will be to endorse it. The next section examines how individuals may cope with identity threat.

\section{Strategies for Averting and Coping with Threat}

IPT theorises socio-psychological action in terms of strategies for 'coping' with real, or preemptively averting, threat to the motivational principles of identity (Breakwell, 1986). Individuals will seek to maintain appropriate levels of identity principles by engaging in such strategies, which are conceptualised as 'any activity, in thought or deed, which has as its goal the removal or modification of a threat to identity' (p. 78). Coping strategies can function at the intra-psychic, interpersonal and/or intergroup levels.

\section{Intra-psychic Strategies}

IPT would predict that individuals will respond to social representations of climate change by engaging in action at the intra-psychic level.

Given that the hegemonic representation of anthropogenic climate change and its related components concerning necessary behaviour change may threaten identity, 
individuals may engage in deflection strategies, such as denial (Hulme, 2009; McCright, 2007). There are various socio-psychological incentives for denying the reality of climate change (Diethelm \& McKee, 2009). Denial of its existence obviates the need for significant behaviour change which might threaten the continuity principle. Thus, the strategy of denying the threatening stimulus (i.e. climate change) enables the individual to do nothing (Breakwell, 1986). Accordingly, denial as a response to threatening stimuli may be regarded as more of an inaction strategy, rather than an action strategy.

Individuals may attempt to reinterpret or redefine social reality in order to protect identity. For instance, sections of the British public do indeed acknowledge the reality of climate change but they may re-interpret it as 'a natural process' which is not dependent upon human actions (Castell, 2010, p. 6). Lowe et al. (2006) note that their participants reconceptualised climate change as 'one of the many' upheavals with which human beings have had to cope in the past, essentially attenuating the novelty, uniqueness and urgency of climate change. The threatening stimulus is not denied but its meanings and implications are re-considered so that it no longer poses a threat. Like outright denial, reinterpretation of the threatening stimulus has the psychological advantage of questioning the necessity of changing one's behaviour, which itself could threaten continuity. Deflection strategies such as denial and reinterpretation will likely ensue from alarmist and fatalist representations of climate change.

Individuals may, conversely, accept the hegemonic representation of anthropogenic climate change and, in principle, accept the implication that behaviour change 
is necessary but disassociate this information from their own behaviour. The compartmentalism strategy consists of 'drawing a strict boundary around the dissatisfying addition to the identity structure [which is] not permitted to contaminate the rest of identity' (Breakwell, 1986, p. 95). The compartmentalisation of the hegemonic representation of anthropogenic climate change means that it is accepted and assimilated to identity but that it need not have implications for other aspects of identity, such as long-standing behavioural practices. Individuals do not actively perceive a link (or refrain from making the link) between their behaviour (e.g. driving a car with high emissions) and the environmental problem of climate change when these are compartmentalised. Therefore, compartmentalism may constitute a psychosocial strategy for safeguarding feelings of continuity, since previous behaviours remain unaffected, and psychological coherence, given that the inconsistency between the hegemonic representation and the "problematic" behaviours is not acknowledged.

These intra-psychic strategies protect identity by deflecting the threats that may be induced by the hegemonic representation of climate change.

\section{Interpersonal and Intergroup Strategies}

One of the unique strengths of our theoretical framework, which brings together IPT and SRT, is that it encompasses not just the individual or intra-psychic level of analysis common in attitudinal research (Kahan et al., 2011), but also the interpersonal, intergroup and societal levels. Responses to identity threat, for example, can occur, and should be studied, at all 
levels (Jaspal \& Breakwell, 2014). At the social level, individuals will engage in interpersonal and intergroup strategies for protecting identity in response to social representations of climate change (Smith \& Joffe, 2013). This is because climate change exists as a social phenomenon, as well as a psychological one.

Human beings typically belong to a number of distinct social groups. It may be possible for individuals to avert identity threat by shifting psychological salience/selfcategorisation from one group membership to another, since particular sets of social representations are often more associated with a given social group membership (Breakwell, 1993, 2001). As a human being (a superordinate group membership), one might be concerned about the potential risks posed by human-induced industrial activity to the well-being of the planet. However, when one's membership in a subgroup category (e.g. American national identity) acquires psychological salience, individuals may come to regard climate change as a geographically distant phenomenon, as is observable in survey-based research in the US (Leiserowitz, 2005). Membership in this subgroup may bring to the psychological forefront a distinct range of priorities and responsibilities, which are reified in social representations associated with this subgroup membership. Thus, social representations associated with the superordinate category 'human being', which have the ability to threaten the principles of continuity, distinctiveness and self-efficacy, can be eschewed when particular subgroup memberships become central to self-definition. Furthermore, Smith and Joffe (2013) note that individuals may use "othering" strategies to protect in-group identity from threat. Researchers should attempt to examine, in a contextually sensitive manner, the risk representations 
associated with individuals' immediate or psychologically salient group memberships in order to predict how and when the strategy of shifting between multiple group memberships may be deployed.

In addition to the group memberships individuals already have, they may actively join or create groups in order to avert identity threat. History has demonstrated that individuals experiencing threat may unite in order to create a new group based around particular social representations. For instance, the socially and economically disadvantaged lower caste groups in India have united with others who share their predicament in order to encourage positive social change (Jaspal, 2011). Such group behaviour can be observed with regard to pro- and anti-environmental groups in the context of climate change (Eckersley, 1989; McCright, 2007).

More generally, it can be hypothesised that individuals will employ deflection strategies when the self-efficacy principle is weakened by alarmist representations of climate change. The particular strategy employed is contingent largely upon the type of social representation (i.e. hegemonic, polemic). Conversely, use of the interpersonal and intergroup strategies depends upon the salience of particular principles in the first instance. For instance, those who value (national) self-efficacy may shift between their group memberships, while those who value belonging might opt for participation in pressure groups. 


\section{Conclusion}

This paper brings a new perspective to the study of climate change that has its roots in recent developments in SRT and IPT (Jaspal \& Breakwell, 2014). This has enabled us to shed new light on links between social representations of climate change, identity and action providing preliminary theoretical insights that are grounded in previous empirical research.

When taking into consideration the role of identity processes, it is possible to predict the acceptance, assimilation and salience of particular social representations of climate change among individuals. Moreover, by bridging SRT and IPT it may even be possible to predict behavioural responses. The synthesis of social representation and identity has been presented through the lens of IPT, which postulates that individuals need to maintain appropriate levels of particular identity principles and that they will behave in ways that restore appropriate levels of the principles when they are threatened. This hybrid approach makes a novel contribution to the field of climate change, given that scholars have recently been arguing for an identity-based approach to climate change (Crompton \& Kasser, 2010; Murtagh et al., 2012). Moreover, this paper makes specific assertions about how elements of identity (e.g. group memberships) and the principles of identity may be affected by particular social representations. The theoretical pay-off may be significant given that this hybrid approach may be relevant to a broader range of environmental issues.

In the context of climate change, continuity seems to constitute a particularly important identity principle, given the perceived threat of climate change (as an environmental problem) to human beings and the potential threats that enforced behaviour 
change can entail for everyday lifestyles. Indeed, Dunwoody (2007) observes that 'strong' beliefs, or beliefs which are central to one's sense of self, will be defended when seen as being contradicted by new incoming information, such as prescriptions about sustainable behaviour in the context of climate change. It seems likely that individuals will respond more favourably to recommendations concerning behaviour change when the recommended change is framed and perceived as being less disruptive to everyday lifestyles. Otherwise, a threat to continuity is likely to activate deflection strategies which in turn block any perceived need for change. Consequently, social constructionist analyses of how climate change and behaviour changes are represented are necessary. More specifically, there is a need to examine empirically how the processes of anchoring and objectification are deployed in channels of societal information in order to identify which social representations are emerging on the cultural landscape.

Enforced behaviour change could threaten feelings of distinctiveness and selfesteem, particularly if the enhancement of these principles is contingent upon the maintenance of existing practices. An important next step in this field is to examine empirically the psychosocial meanings of particular social practices and their effects for identity processes in specific cultural groups and communities - this will reveal the sociopsychological outcomes of requiring a transition to more sustainable behaviours and practices and the likelihood of their acceptance and assimilation by the general public. It is unlikely that individuals will endorse a behaviour or practice that does not provide appropriate levels of self-esteem, distinctiveness and so on. 
We also draw attention to the links between social representations, identity processes and possible coping strategies. Individuals may engage in deflection strategies (e.g. denial, reinterpretation) when confronted with identity-threatening representations of climate change (Breakwell, 1986). We hypothesise that deflection strategies will likely ensue from exposure to alarmist and fatalist representations of climate change, given that these representations typically provide the individual with no other way in which to respond (Breakwell, 2010). On the other hand, when representations of climate change are collectively and pervasively regarded as threatening for identity, it is likely that individuals will engage in intergroup strategies such as the formation of pressure groups in order to tackle the threat or, indeed, affirm its existence (McCright, 2007).

In conclusion, this paper provides preliminary insight into an integrative theoretical framework in which social representations of climate change, identity and sociopsychological action can be collectively examined. This framework makes a useful contribution to social sciences research into climate change, given that it theorises the interrelations between construction, perception and behaviour. In this paper, we do not attempt to provide a polished communication model for campaigners but rather a theoretical "tool-kit" for conducting systematic empirical research into representation, cognition and action and the inter-relations between them. However, systematic and multi-methodological empirical research, based on the hypotheses developed in this paper, should inform future models of communicating climate change and other environmental issues. At a more general level, it is necessary to take into account the psychosocial meanings that both climate and enforced 
behaviour change can have for the diverse groups and communities affected by climate change, a global social, psychological and environmental issue. A key strength of the framework is its encompassing of multiple levels of analysis, moving from intra-psychic through interpersonal and intergroup, to societal levels of analysis. Given this breadth, our framework also provides a way of integrating qualitative and quantitative research methods, both of which can provide valuable insights into what environmental issues, such as climate change, mean to groups and individuals.

\section{Acknowledgements}

We would like to thank the ESRC for their financial support of project RES-360-25-0068. An earlier version of this paper was presented at the Culture, Politics and Climate Change Conference, University of Colorado-Boulder, Boulder, USA, 13th-15th September 2012.

\section{References}

Abrahamse, W., Gatersleben, B. \& Uzzell, D. (2009). Encouraging sustainable food consumption: The role of (threatened) identity, RESOLVE Working Paper Series, 0409, University of Surrey, June 2009.

Agyeman, J., Doppelt, B., Lynn, K. \& Hatic, H. (2007). The climate-justice link: Communicating risk with low income and minority audiences. In S. Moser \& L. Dilling (eds.), Creating a climate for change (pp. 119-138). Cambridge: Cambridge University Press

Bord, R.J., O’Connor, R.E. \& Fisher, A. (2000). In what sense does the public need to understand global climate change? Public Understanding of Science, 9, 205-218.

Bostrom, M. (2001). American attitudes to the environmental and global warming: an overview of public opinion. Study conducted for the FrameWorks Institute, 
Washington, DC.

Bostrom, A. \& Lashof, D. (2007). Weather it's climate change? In S.C. Moser \& L. Dilling (eds.), Creating a climate for change (pp. 31-43). Cambridge: Cambridge University Press.

Boykoff, M.T. \& Boykoff, J.M. (2004). Bias as balance: Global warming and the U.S. press. Global Environmental Change, 14, 125-136

Breakwell, G.M. (1986). Coping with threatened identities. London: Methuen.

Breakwell, G.M. (1993). Social representations and social identity. Papers on Social Representations, 2(3), 1-20.

Breakwell, G.M. (2001). Social representational constraints upon identity processes. In K. Deaux \& G. Philogène (eds.), Representations of the social: Bridging theoretical traditions (pp. 271-284). Oxford: Blackwell.

Breakwell, G.M. (2010). Models of risk construction: Some applications to climate change. Wiley Interdisciplinary Reviews: Climate Change, 1(6), 765-907.

Breakwell, G.M. \& Millward, L.J. (1997). Sexual self-concept and sexual risk taking. Journal of Adolescence, 20, 29-41.

Carvalho, A. (2007). Ideological cultures and media discourses on scientific knowledge: rereading news on climate change. Public Understanding of Science, 16(2), 223-243.

Castell, S. (2010). What the public say about climate change and low carbon interventions. London: Department for Business Innovation and Skills.

Crompton, T., \& Kasser, T. (2010). Human identity: A missing link in environmental campaigning. Environment, 52(4), 23-33.

Diethelm, P. \& McKee, M. (2009). Denialism: What is it and how should scientists respond? European Journal of Public Health, 19(1), 2-4.

Dryzek, J.S., Norgaard, R.B. \& Schlosberg, D. (2011). The Oxford handbook of climate 
change and society. Oxford: Oxford University Press.

Dunwoody, S. (2007). The challenge of trying to make a difference using media messages. In

S.C. Moser \& L. Dilling (eds.), Creating a climate for change (pp. 89-104).

Cambridge: Cambridge University Press

Eckersley, R. (1989). Green politics and the new class: Selfishness or virtue? Political Studies, 37, 205-223.

Exley, S. \& Christie, I. (2003). Stuck in our cars? Mapping transport preferences. In A. Park, J. Curtice, K. Thomson, L. Jarvis \& C. Bromley (eds.), British social attitudes (pp. 45-70). London: Sage.

Hansen, J., Winzeler, S. \& Topolinski, S. (2010). When the death makes you smoke: A terror management perspective on the effectiveness of cigarette on-pack warnings. Journal of Experimental Social Psychology, 46, 226-28.

Höijer, B. (2010). Emotional anchoring and objectification in the media reporting on climate change. Public Understanding of Science, 19(6), 717-731.

Houghton, J.T., Ding, Y., Griggs, D.J., Noguer, M., van der Linden, P.J., Dai, X. \& Johnson, C.A. (eds.) (2001). Climate change 2001:The scientific basis. Contribution of working group one to the Third Assessment Report of the Intergovernmental Panel on Climate Change. Cambridge: Cambridge University Press.

Hulme, M. (2009). Why we disagree about climate change. Cambridge: Cambridge University Press.

Irwin, A. (1995). Citizen science: A study of people, expertise and sustainable development. London: Routledge.

Jaspal, R. (2011). Caste, social stigma and identity processes. Psychology and Developing Societies, 23(2), 27-62.

Jaspal, R. \& Breakwell, G.M. (2014). Identity process theory: Identity, social action and 
social change. Cambridge: Cambridge University Press.

Jaspal, R. \& Nerlich, B. (2013). When climate science became climate politics: British media representations of climate change in 1988. Public Understanding of Science. (Online First, doi: 10.1177/0963662512440219)

Jaspal, R., Nerlich, B. \& Koteyko, N. (2013). Contesting science by appealing to its norms: Readers discuss climate science in The Daily Mail. Science Communication. $35(3), 383-410$

Kahan, D. (2010). Fixing the communications failure. Nature, 463, 296-297.

Kahan, D.M., Jenkins-Smith, H. \& Braman, D. (2011). Cultural cognition of scientific consensus. Journal of Risk Research, 14, 147-74.

Lazo, J. K., Kinnell, J. C. \& Fisher, A. (2000). Expert and layperson perceptions of ecosystem risk. Risk Analysis, 20, 179-193.

Leiserowitz, A. (2003). Global warming in the American mind: The roles of affect, imagery, And worldviews in risk perception, policy preferences and behavior. Unpublished PhD dissertation, University of Oregon, Eugene.

Leiserowitz, A. (2005). American risk perceptions: Is climate change dangerous? Risk Analysis, 25(6), 1433-42.

Leiserowitz, A. (2006). Climate change risk perception and policy preferences: The role of affect, imagery, and values. Climatic Change, 77, 45-72.

Leiserowitz, A. (2007). Communicating the risks of global warming: American risk perceptions, affective images and interpretive communities. In S.C. Moser \& L. Dilling (eds.), Creating a climate for change (pp. 44-63). Cambridge: Cambridge University Press.

Leiserowitz, A., Maibach, E., Roser-Renouf, C. \& Hmielowski, J. (2012). Global warming’s six Americas, March 2012 \& Nov. 2011. Yale University and George Mason 
University. New Haven, CT: Yale Project on Climate Change Communication.

Lorenzoni, I., Leiserowitz, A., Doria, M.F., Poortinga, W. \& Pidgeon, N.F. (2006). Cross-

national comparisons of image associations with 'global warming' and 'climate change' among laypeople in the United States of America and Great Britain. Journal of Risk Research, 9(3), 265-81.

Lowe, T., Brown, K., Dessai, S., Doria, M., Haynes, K \& Vincent, K. (2006). Does tomorrow ever come? Disaster narrative and public perceptions of climate change. Public Understanding of Science, 15, 435-57.

Marková, I. (2003). Dialogicality and social representations. Cambridge: Cambridge University Press

McCright, A.M. (2007). Dealing with climate change contrarians. In S.C. Moser \& L. Dilling (eds.), Creating a climate for change (pp. 200-212). Cambridge: Cambridge University Press.

Milne, S., Sheeran, P. \& Orbell, S. (2000). Prediction and intervention in health-related behaviour: A meta-analytic review of protection motivation theory. Journal of Applied Social Psychology, 30, 106-143.

Minivan News (2012). Silicon Valley joins the Maldives on sea level rise threat list: Forbes. Minivan News, April 15 2012. Available at http://minivannews.com/news-inbrief/silicon-valley-joins-the-maldives-on-sea-level-rise-threat-list-forbes-35455

Moscovici, S. (1988). Notes towards a description of social representations. European Journal of Social Psychology, 18, 211-250.

Moscovici, S. \& Hewstone, M. (1983). Social representations: From the 'naive' to the 'amateur' scientist. In M. Hewstone (ed.) Attribution theory: Social and functional extensions (pp. 99-125). Oxford: Basil Blackwell.

Moser, S.C. (2007). More bad news: The risk of neglecting emotional responses to climate 
change information. In S.C. Moser \& L. Dilling (eds.), Creating a climate for change (pp. 64-81). Cambridge: Cambridge University Press.

Moser, S.C. \& Dilling, L. (eds.) (2007). Creating a climate for change. Cambridge: Cambridge University Press.

Murtagh, N., Gatersleben, B. \& Uzzell, D. (2012) Self-identity threat and resistance to change: Evidence on regular travel behaviour. Journal of Environmental Psychology, $32(4), 318-326$.

Nerlich, B. (2010). 'Climategate': Paradoxical metaphors and political paralysis. Environmental Values, 19(4), 419-442.

Nicholson-Cole (2004). Imag(in)ing climate change: Exploring people's visual imagery, issue salience and personal efficacy. Unpublished $\mathrm{PhD}$ dissertation, University of East Anglia, UK.

Norgaard, K.M. (2011). Climate change, emotions and everyday life. Cambridge, MA: MIT Press.

Olausson, U. (2010). Towards a European identity? The news media and the case of climate change. European Journal of Communication, 25(2), 138-152.

Olausson, U. (2011). "We're the ones to blame": Citizens' representations of climate change and the role of the media. Environmental Communication: A Journal of Nature and Culture 5(3), 281-299.

Pernetta, J.C. (1992). Impacts of climate change and sea-level rise on small island states: National and international responses. Global Environmental Change, 2(1), 19-31.

Poortinga, W., Spence, A., Whitmarsh, L., Capstick, S. \& Pidgeon, N.F. (2011). Uncertain climate: An investigation into public scepticism and anthropogenic climate change. Global Environmental Change, 21(3), 1015-1024.

Prillwitz, J. \& Barr, S. (2009). Motivations and barriers to adopting sustainable travel 
behavior, ProST Working Paper, Department of Geography, University of Exeter.

Risbey, J. (2008). The new climate discourse: Alarmist or alarming? Global Environmental Change, 18(1), 26-37.

Ruiter, R. A. C., Abraham, C. J., \& Kok, G. (2001). Scary warnings and rational precautions: A review of the psychology of fears appeals. Psychology and Health, 16, 613-630.

Smith, N. \& Joffe, H. (2013). How the public engages with global warming: A social representations approach. Public Understanding of Science, 22, 16-32.

Steg, L. \& Gifford, R. (2008). Social psychology and environmental problems. In L. Steg, A. P. Buunk, \& T. Rothengatter (Eds.), Applied social psychology: Understanding and managing social problems (pp. 1-27). New York: Cambridge University Press.

Stern, P. (2000). Toward a coherent theory of environmentally significant behavior. Journal of Social Issues, 56, 407-424.

Sterngold, A., Warland, R.H. \& Herrman, R.A. (1994). Do surveys overstate public concern? Public Opinion Quarterly, 58, 255-63.

Thrush, D., Fife-Schaw, C. \& Breakwell, G.M. (1999). An evaluation of two school-based interventions to reduce smoking prevalence among 9-13 year olds. Swiss Journal of Psychology, 58, 85-100.

Wall, R., Devine-Wright, P., \& Mill, G. A. (2007). Comparing and combining theories to explain pro-environmental intentions: The case of commuting-mode choice. Environment and Behavior, 39(6), 731-753.

Weingart, P., Engels, A. \& Pansegrau, P. (2000). Risks of communication: Discourses on climate change in science, politics and the mass media. Public Understanding of Science, 9(3), 261-283.

Whitmarsh, L. (2008). Are flood victims more concerned about climate change than other people? The role of direct experience in risk perception and behavioural response. 
Journal of Risk Research, 11(3), 351-74. 